\title{
Effect on the Mechanical Properties of Al 7075 Reinforced with SiC and TiC Particles
}

\author{
M.Subramanian, B.Aravinth
}

\begin{abstract}
In the present industrial scenario, Aluminium and its alloy based composites have more importance in the growing fields of engineering. Aluminium reinforced metal matrix composites are broadly speaking desired because it has the excessive strenth along with less weight, hardness, corrosion resistance, fatigue and creep resistance. The Al composites are focused to use in aerospace, automobile and also in structural domain because it gives good strength with less weight. This paper discussed about the mechanical residences of Aluminium 7075 alloy strengthened with SiC and TiC. Stir casting process was utilized for fabrication of composites and composite specimens are subjected to tensile test by using Universal Testing Machine. The composite hardness was tested by using Brinell hardness tester and the Charpy impact tester used for findings the impact strength. An experimental results are compared with unreinforced alloy of Al 7075. Micro structural characterization confirms the particles of reinforcement are distributed to the entire structure of matrix. The experimental result shows the mechanical properties slightly increased by varying wt\% of reinforcements in the matrix material. The better tensile strength (252MPa), hardness (83HB) and impact strength (4.6 Joules) is obtained by the composition of $60 \%$ wt of Al 7075, 20\% wt of TiC and $20 \%$ wt of SiC.
\end{abstract}

Keywords : Al 7075, Hardness, SiC and Stir Casting.

\section{INTRODUCTION}

$\mathrm{T}$ he composites are having ability materials for diverse applications owing to their precise properties of physical along with mechanical. The adding reinforcements with matrix material for enriching the mechanical properties when compared to conventional materials. A vehicle's performance and complex behavior are highly determined by its weight. Lightweight architecture is more of a challenge than ever in automotive engineering, taking into account convenience, protection and pollution in new vehicles. Against this context, the production of materials plays an essential role when substantial weight loss is made feasible by substituting high density materials and more precisely adapting material specifications to the practical requirements of the parts.

Revised Manuscript Received on October 20, 2020.

* Correspondence Author

Dr.M.Subramanian, Professor in Mechanical Engineering, SNS College of Technology, Coimbatore, India

B.Aravinth*, Assistant Professor in Mechanical Engineering, Dr.Navalar Nedunchezhiyan College of Engineering, Cuddalore, India, Email: aravinthb2020@gmail.com

(c) The Authors. Published by Blue Eyes Intelligence Engineering and Sciences Publication (BEIESP). This is an open access article under the CC BY-NC-ND license (http://creativecommons.org/licenses/by-nc-nd/4.0/)
Therefore, hardened light metals, because of their strong strength to weight ratio, provide a promising solution. The metal matrix composites are metals that incorporate particles, whiskers, and fibers made of different composition materials. These materials will be tailored to be light-weight and with varied different properties including: high strength, high coefficient of elasticity, high toughness and impact resistance, low sensitivity to changes in temperature or thermal shock, high surface sturdiness, low sensitivity to surface flaws, high electrical and thermal conduction, minimum exposure to the potential downside of wetness absorption leading to environmental degradation, and improved the method of fabrication with standard metal operating instrumentation. The study is focused to fabricate of Aluminium 7075 hybrid composites containing a variable volume fraction of particles ( $\mathrm{SiC}$ and $\mathrm{TiC}$ ).

\section{LITERATURE SURVEY}

Zhang, H. (2008) have studied the Al-7075 reinforced SiC composites are fabricated through spray deposition technique for finding deformation and also fracture of the composite. Baradeswaran et.al. (2014) developed of Al7075 hybrid metal matrix composite through stir casting method. The findings showed increase in toughness, ultimate tensile strength, flexural strength, wear resistance thus growing the $\mathrm{Al} 2 \mathrm{O} 3$ reinforcement weight fraction. Efzan (2016) prepared LM 6 alloy reinforced different $\mathrm{wt} \%$ of $(0 \%, 4 \%, 5 \%$ and $6 \mathrm{wt} . \%)$ fly ash particles based composite produced by compo casting and it observed that the macro-hardness and the UTS increases with varying wt $\%$ of fly ash particles. Selvam (2013 ) developed composite AA6061 / fly ash and assessed composite mechanical and micro-structural characterization. It concluded that an improvement in the weight of fly ash particles in the aluminium matrix and superior qualities in contrast with base alloy. Ramesh CS (2011) studied mechanical properties for Al 6061-TiB2 in-situ composites fabricated by liquid metallurgy and the evolved in-situ composites exhibited full-size improvement of mechanical properties as compared to the base metal. Muruganandan et al. (2015) used Aluminium 7075 is matrix material with fly ash and TiC as reinforcement materials. An evaluation has made among the reinforced and unreinforced alloys which include $\mathrm{Al}$ 6061, Al 7075 and concluded that the mechanical properties of composite is extended by using various the wt\% of fly ash and titanium carbide. From the above discussion, there are not sufficient records available at the mechanical properties of particulate

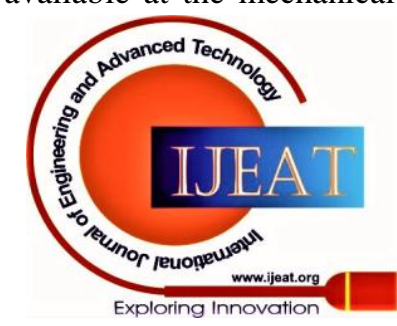




\section{Effect on the Mechanical Properties of Al 7075 Reinforced with SiC and TiC Particles}

(SiC and $\mathrm{TiC}$ ) strengthened $\mathrm{Al} 7075$ composites.

\section{MATERIALS}

The matrix is the monolithic material into which reinforcement is embedded. It is completely continuous and surrounds other phases. Reinforcements are distributed randomly throughout the matrix. Reinforcement is the secondary part of the composite which it provides strength, stiffness and has transfer the load to the entire structure. Aluminium 7075 (Al7075) is selected because of the matrix material because it's far low price and has higher properly like thermal conductivity, high shear power, abrasion resistance, and high-temperature operation. It possesses outstanding properties of casting and fair strength. This alloy is ideally suited for lightweight metal castings in industrial manufacturing.

Silicon carbide ( $\mathrm{SiC})$ : Silicon carbide (SiC) is a combination of silicon and carbon. Silicon carbide is mainly used as abrasive particles in grinding wheel because it has excessive thermal conductivity, excessive-temperature power, low thermal growth, and resistance to chemical response, makes $\mathrm{SiC}$ precious in the manufacture of high-temperature bricks and different refractoriness.

Titanium carbide (TiC): Titanium carbide is an artificial, excessive-melting, heat-resistant cloth which is broadly used for production metal-running tools, defensive coatings and carbide steel and also it is used in resistant packages, thin movie ultra capacitors, bearings, nozzles, reducing gear, and many others. SiC and $\mathrm{TiC}$ are used as a reinforcement material in this study.

\section{EXPERIMENTAL PROCEDURE}

Before The composite specimens were prepared with help of stir casting method. Table 1 shows the composition of different reinforcements which were added in matrix material $\mathrm{Al}$ 7075. The dry crucible and furnace are used for composite removing moisture inside the furnace and Al 7075 alloy rod was used. At the beginning of melting a $150 \mathrm{~g}$ of Aluminium scraps is heated and melted to a molten stage by utilizing the Stir casting apparatus and then the weighted $\mathrm{Al} 7075$ rods are added as per the compositions and the temperature is raised to $840^{\circ} \mathrm{C}$ for complete melting to form a molten liquid state.
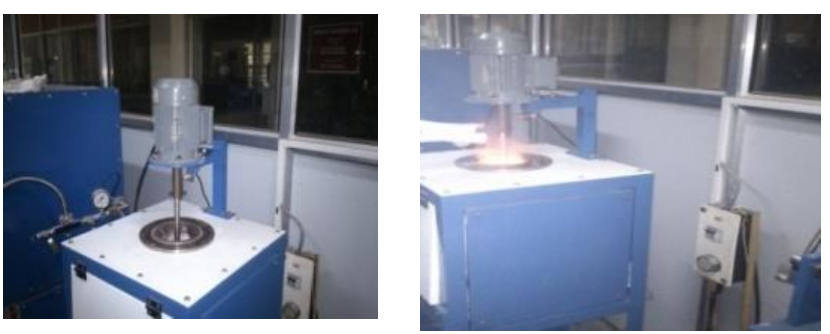

Fig. 1, 2 setup of stir casting and melting of Aluminium 7075

Figure 1 and 2 shows setup of stir casting and melting of Aluminium 7075 . The preheated $\left(40^{\circ} \mathrm{C}\right) \mathrm{TiC}$ powder is added into matrix molten metal then mechanical stirrer is rotated at150 rpm for complete mixing of the particle reinforcement into a matrix. After that weighted SiC powder is added and the stirrer is rotated at $200 \mathrm{rpm}$ for avoiding settle down of Silicon Carbide particles in the furnace. The $150 \mathrm{mg}$ of Magnesium is fabrication. Initially, the electric furnace is set at $150^{\circ} \mathrm{C}$ for

added for improving the wettability. Then the complete melting molten metal transferred constantly into the prepared steel mould die to avoid gas bubbles formations and then its allowed to solidify. The machining is done in the lathe to get required size and shape as per required ASTM standards for conducting mechanical test.

Table 1 Composition of different reinforcements and matrix material

\begin{tabular}{|c|c|c|c|}
\hline \multirow{2}{*}{ S.NO. } & \multirow{2}{*}{$\begin{array}{c}\text { Matrix Al } \\
7075\end{array}$} & \multicolumn{2}{|c|}{$\begin{array}{c}\text { Reinforcement Materials } \\
\text { (Wt \%) }\end{array}$} \\
\cline { 3 - 4 } & Wt \% & TiC & SiC \\
\hline $\mathrm{C}_{1}$ & 100 & - & - \\
\hline $\mathrm{C}_{2}$ & 90 & 5 & 5 \\
\hline $\mathrm{C}_{3}$ & 80 & 10 & 10 \\
\hline $\mathrm{C}_{4}$ & 70 & 15 & 15 \\
\hline $\mathrm{C}_{5}$ & 60 & 20 & 20 \\
\hline
\end{tabular}

\section{RESULT AND DISCUSSION}

\section{a) Tensile Test}

Tensile strength is a calculation of the force used to lift anything to the stage before it falls and the Universal Testing Machine (UTM) test was used. The Specimen used for testing according to ASTM E8 standard. The figure 3 shows Tensile strength for MMCs. It may inferred that $\mathrm{SiC}$ and $\mathrm{TiC}$ debris are very powerful in enhancing the tensile strength from 210 MPa to 252 MPa because of the strengthening mechanism by the reinforcement. The inclusion of reinforcing particles in the matrix causes substantial resistance to matrix alloys by supplying greater tensile stress resistance. Higher dislocation intensity in the matrix and load is induced by the thermal imbalance among matrix and reinforcement-bearing power of the hard particles, which consequently improves composite strength

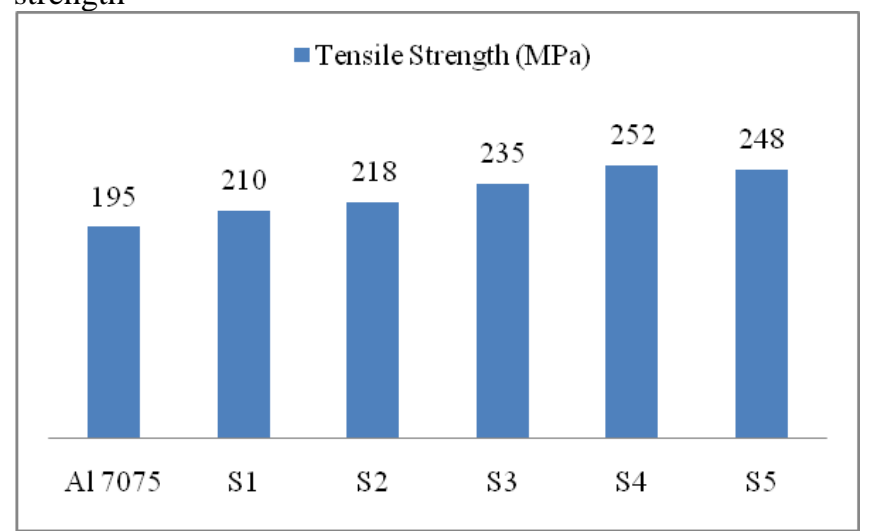

Fig.3 Tensile strength of the composite and Al 7075 b) Hardness Test

Hardness is the material resistance to restricted deformation when applying the load. A tough material surface resists indentation or scratching and has the ability to indent or cut other substances. The hardness of the composite was examined with the help of Brinell Hardness Tester. Within the Brinell hardness tester, a hardened steel ball is pressed into the flat surface of a work piece with distinct pressure. The ball is then removed and the diameter of indentation has measured using a microscope.

\section{Published By:}

Blue Eyes Intelligence Engineering and Sciences Publication

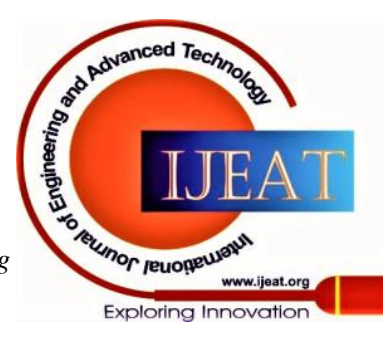


It is observed from experimental results hardness of MMCs is increased when the amount of reinforcement particulates increases. At the presence of such difficult surface place of debris gives greater resistance to plastic deformation which showing in results in increase the hardness of composites. It's far cautioned that the availability of hard ceramic segment inside the soft ductile matrix reduces the ductility for composites because discount of ductile metal content which notably increases the hardness. Figure 4 represents the hardness test specimen and figure 5 shows the hardness of the composite.

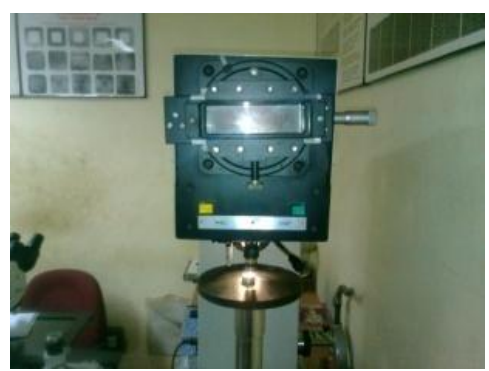

Fig 4. Hardness test specimen

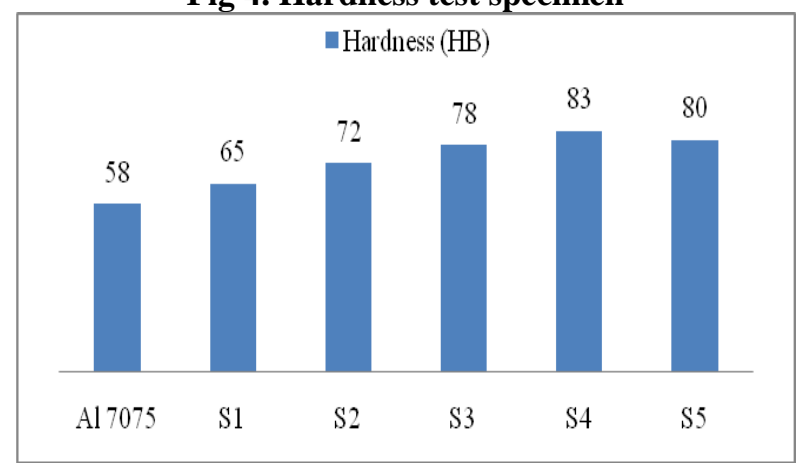

Fig. 5 hardness value of the composite and matrix material

\section{c) Impact test}

Inside the impact test type of notched bar material is used both as a cantilever and truly supported beam, is broken by one blow in such how that the overall strength had to fracture it will be determined. The energy needed to fracture a material is of importance in cases of shock loading once a part or structure is also needed to absorb the K.E of a moving object. The absorbed energy by the materials was calculated in joules. The energy absorbed is found with the assistance of Charpy impact tester. The standard specimen size used for conducting Charpy impact test and observed that the impact strength is increased by varying wt\% of the $\mathrm{SiC}$ and $\mathrm{TiC}$ particles within the matrix material. Figure 6 shows the impact strength of reinforced composites and pure Al 7075 alloy.

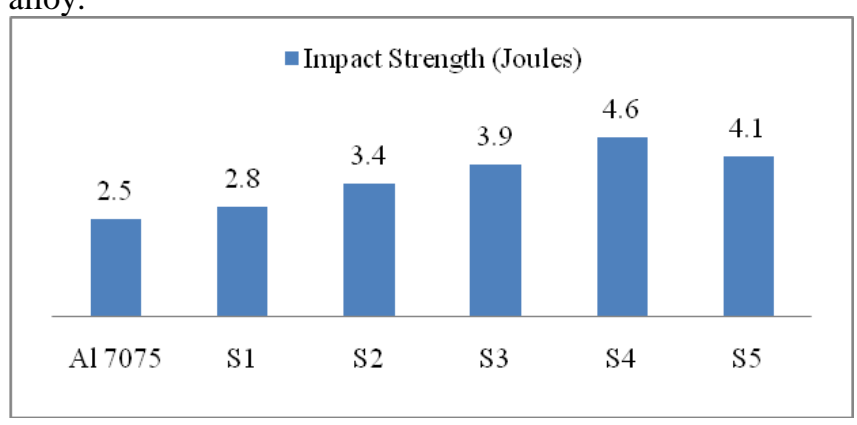

Fig.6 Impact strength of the Al 7075 and its composite d) Microstructure

The composite samples are ultrasonically washed and assaulted to expose their microstructure with Keller reagent.
The Microstructure is analyzed by using SEM. The microstructure have revealed that there is a uniform distribution of particles reinforcement within the matrix material. The figure 7 shows the SEM images of Aluminium based hybrid MMCs.
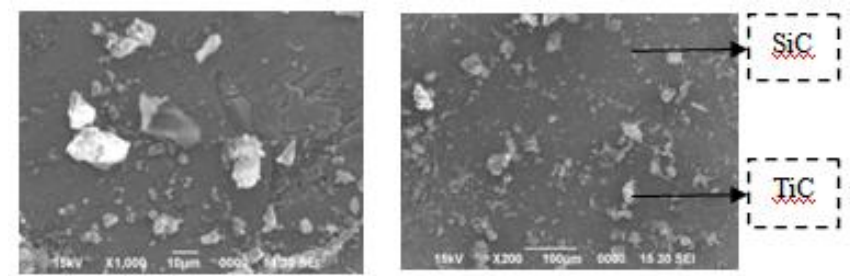

Fig.7 SEM images of hybrid metal matrix composite

\section{CONCLUSION}

Composites were effectively manufactured by utilizing techniques of stir casting and the SEM display reasonably standardized distribution in the Al7075 metal matrix of reinforcement particles. It is demonstrated that the hardness improves with the matrix varying wt\% of reinforcing materials. An increased in tensile strength, impact strength and also stiffness has culminated in the particle inclusion by $\mathrm{TiC}$ and SiC. The tensile strength increased when changing the wt $\%$ of reinforcement particles in base alloy. However, further advances in functional properties also culminated in the inclusion of these reinforcement products. As the reinforcement content increases the tensile strength, impact strength and hardness increases up to $15 \mathrm{wt} \%$ of $\mathrm{TiC}$ and $\mathrm{SiC}$ reinforcement and slightly decreases at $20 \mathrm{wt} \% \mathrm{SiC}$ and $\mathrm{TiC}$ reinforcement. From the investigation, it was concluded that composites containing 15wt\% Titanium carbide and $15 \mathrm{wt} \%$ $\mathrm{SiC}$ reinforcements exhibited better mechanical properties.

\section{REFERENCES}

1. A. R. K. Swamy, A. Ramesh, G.B. Veeresh Kumar, J. N. Prakash "Effect of Particulate Reinforcements on the Mechanical Properties of Al6061-WC and Al6061-Gr MMCs", Journal of Minerals \& Materials Characterization \& Engineering, Vol. 10, No.12,(2011), pp.1141-1152.

2. A. Ramesh, J. N. Prakash, A. S. Shiva ShankareGowda and SonnappaAppaiah. "Comparison of the Mechanical Properties of Al6061/Albite and Al6061/Graphite Metal Matrix Composites", Journal of Minerals \& Materials Characterization \& Engineering, Vol. 8, No.2,(2009), pp 93-106.

3. Ankesh Kumar, Study of Physical, Mechanical and Machinability Properties of Aluminium Metal Matrix Composite Reinforced with Coconut Shell Ash particulates, Imperial Journal of Interdisciplinary Research, Vol-2, Issue-5, 2016 ISSN: 2454-1362.

4. Baradeswaran, A., ElayaPerumal, A., (2014). Study on mechanical and wear properties of $\mathrm{Al}$ 7075/Al2O3/graphite hybrid composites. Composites Part B: Engineering 56(0): 464-471.

5. Deepak Singla, Evaluation of Mechanical Properties of Al 7075-Fly Ash Composite Material, International Journal of Innovative Research in Science, Engineering and Technology Vol. 2, Issue 4, April 2013.

6. Efzan MNE, Syazwani NS, Abdullah MMAB, Microstructure and mechanical properties of fly ash particulate reinforced in LM6 for energy enhancement in automotive applications, IOP Conference Series, Materials Science Engineering, 133, 2016, 1-12.

7. Feng, A.H., Xiao, B.L. and Ma, Z.Y. "Effect of microstructure evolution on mechanical properties of friction stir welded AA2009S/SiCp composite", Compos. Sci. Technol., 68(9), 2008, 2141-2148

Published By:

Blue Eyes Intelligence Engineering and Sciences Publication

(C) Copyright: All rights reserved.

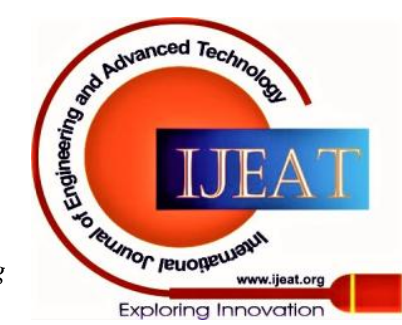




\section{Effect on the Mechanical Properties of Al 7075 Reinforced with SiC and TiC Particles}

8. I.Mobasherpour, A.A. Tofigh and M. Ebrahimi , 'Effect of nano-sizeAl2O3 reinforcement on the mechanical behavior of synthesis 7075aluminum alloy composites by mechanical alloying', Mat. Che. and Phy., Vol. 138, pp.535-541, 2013.

9. Kumar GBV, Rao CSP, Selvaraj N, Bhagyashekar MS (2010) Studies on Al6061-SiC and Al7075-Al2O3 Metal Matrix Composites. Journal of Minerals and Materials Characterization and Engineering, pp 43-55.

10. L.Ceschini, "Tensile and fatigue properties of the AA6061/20\% volume Al2O3p and AA7005/10\% volume Al2O3p composites", Composites Science and Technology 66 (2006) 333-342.

11. Lal Krishna, Development of Silicon Carbide Reinforced Aluminium Metal Matrix composite For Hydraulic Actuator In Space Applications, International Journal of Research in Engineering \& Technology, ISSN(E): 2321-8843; ISSN(P): 2347-4599,Vol. 3, Issue 8, Aug 2015, 41-50.

12. P. Muruganandhan, M. Eswaramoorthi, and K. Kannakumar, "Aluminium fly ash composite - an experimental study with mechanical properties perspective", Int. J. Eng. Res., vol. 3, pp.78-83, 2015.

13. Prashant Kumar Suragimath and Dr. G.K. Purohit, 'A Study on Mechanical Properties of Aluminium Alloy (LM6) Reinforced with SiC and Fly Ash', IOSR J. of Mech. and Civil Eng. , Vol. 8, No.5, pp.13-18, 2013.

14. Ramesh CS, Pramod S, Keshavamurthy R. A study on microstructure and mechanical properties of Al 6061-TiB2 in-situ composites. Materials Science and Engineering A. 528, 2011, 4125-32.

15. Ramesh, C.S., Keshavamurthy, R., Chennabasappa, B.H., and Abrar Ahmad. "Microstructure and mechanical properties of Ni-P coated Si3N4 reinforced Al6061 composites", Mater. Sci. Eng., A 502(2), 2009, 99-106.

16. S.K.Ravesh, and T.K. Garg, "Preparation \& analysis for some mechanical property of aluminium based metal matrix composite reinforced with SiC\& fly ash”, Int. J.Eng. Res. Appl., vol. 2, pp.727731, 2012.

17. S.V. Prasad, "Aluminum metal-matrix composites for automotive applications: tribological considerations", Tribology Letters, Vol. 17, No. 3, October 2004

18. Selvam JDR, Smart DSR, Dinaharan I, Microstructure and some mechanical properties of fly ash particulate reinforced AA6061 aluminum alloy composites prepared by compocasting, Materials and Design, 49, 2013, 28-34.

19. T.V.Christy, N.Murugan and S.Kumar, "A Comparative Study on the Microstructures and Mechanical Properties of Al 6061 Alloy and the MMC Al 6061/TiB2/12P", Journal of Minerals \& Materials Characterization \& Engineering, 2010 Vol. 9, No.1, pp.57-65.

20. V. Balaji, N. Sateesh and M. 'Manufacture of Aluminium Metal Matrix Composite (Al7075-SiC) by Stir Casting Technique', Mat. Today Pro. Vol. 2, pp.3403 - 3408, 2015.

21. V. Balaji, N. Sateesh and M. Manzoor Hussain , 'Manufacture of Aluminium Metal Matrix Composite (Al7075-SiC) by Stir Casting Technique', Mat. Today Pro. Vol. 2, pp.3403 - 3408, 2015.

22. Viney Kumar ,Rahul Dev Gupta and N.K. Batrab, 'Comparison of Mechanical Properties and effect of sliding velocity on wear properties of Al 6061, Mg 4\%, Fly ash and $\mathrm{Al} 6061, \mathrm{Mg} 4 \%$, Graphite 4\%, Fly ash Hybrid Metal matrix composite', Pro. Mat. Sci., Vol. 6, pp.1365 1375, 2014.

23. Zhang, H., He, Y., Li, L., (2008). Tensile deformation and fracture behavior of spray-deposition 7075/15SiCp aluminum matrix composite sheet at elevated temperatures. Materials Characterization 59(8): 1078-1082.

24. M. Nataraj and P. Ramesh, (Dec 2016) "Experimental Study on the Mechanical Properties of Aluminum based Hybrid Metal Matrix Composite", International Journal of Printing, Packaging \& Allied Sciences Research, Vol. 4 No. 5 pp. 3431-3438, ISSN: 2320-4387

25. M. Nataraj and P. Ramesh, (June 2016) "Investigation on Machining Characteristics of Al 6061 Hybrid Metal Matrix Composite Using Electrical Discharge Machine", Middle-East Journal of Scientific Research, Vol. 24 No. 6 pp. 1932-1940, ISSN: 1990-9233.

26. Ramesh P and Nataraj M (August 2018) "Automotive industry application of Aluminium based hybrid metal matrix composite", International Journal of Heavy Vehicle Systems, Accepted, ISSN: $1741-5152$

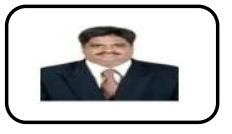

\section{AUTHORS PROFILE}

Dr. M. Subramanian, Professor and Head in the Department of Mechanical Engineering, SNS College of Technology, Coimbatore, India. He has competed
$\mathrm{BE}, \mathrm{ME}$ and $\mathrm{PhD}$ in Anna University, Chennai. He has more than 15 years teaching experience and he has conducted many workshop and conferences .He has published more than thirty research paper in national and International Journals. His area of research is CNC machining, End Milling, Optimization, Material Science and Finite Element Analysis. He has membership in ISTE.

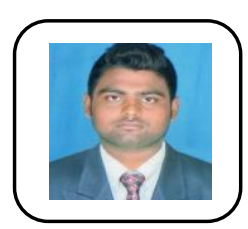

B.Aravinth, Assistant Professor in Mechanical Engineering, Dr.Navalar Nedunchezhiyan College of Engineering, Cuddalore, India. He has completed his BE Mechanical Engineering in 2014 and ME in 2016. He has four years experience in teaching. He has attended many workshops and conferences. His area of research is Composite material, material Science, Manufacturing, thermal Engineering. He is membership in ISTE.

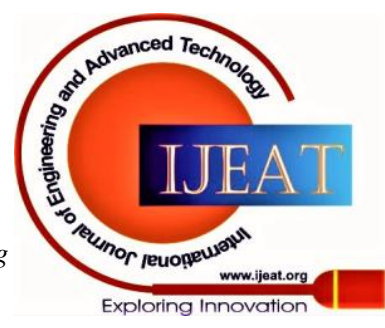

